\section{Commentary: Vein grafts in coronary surgery: Time for an upgrade!}

\author{
James Tatoulis, AM, MBBS, MS, MD, FRACS, \\ FCSANZ
}

Despite mounting evidence for the prognostic benefit of multiarterial grafting (MAG) including use of the radial artery over the past 20 years, left internal thoracic artery (LITA) plus saphenous vein grafts (SVG) remains the dominant operation for coronary artery bypass grafting (CABG) worldwide, accounting for more than $90 \%$ of $\mathrm{CABG} .{ }^{1}$ Consequently, SVGs comprise more than $80 \%$ of individual coronary artery bypass conduits. ${ }^{2}$

LITA + SVG has remained essentially unchanged for more than 30 years. Concurrently, percutaneous revascularization has progressed significantly with advances in stent technology and associated antithrombotic therapeutics.

Adopting MAG will take time. Consequently, SVG will remain the majority conduit even though SVG patency is compromised, with 10 -year failure rates of up to $50 \%{ }^{3}$ There is a need to improve SVG patency in parallel with developments in MAG. Vervoort and colleagues ${ }^{4}$ recognized this, providing an excellent and timely overview, that evaluates the current status of SVG, methods under investigation, and future opportunities to improve SVG patency. They focus on 6 areas, and several will have possible traction.

The no-touch SVG technique, usually through long open incisions, although promising, is based on results predominantly from one center. It is severely compromised by

\footnotetext{
From the Department of Cardiothoracic Surgery, Royal Melbourne Hospital; and Department of Surgery, University of Melbourne, Melbourne, Australia. Disclosures: The author reported no conflicts of interest.

The Journal policy requires editors and reviewers to disclose conflicts of interest and to decline handling or reviewing manuscripts for which they may have a conflict of interest. The editors and reviewers of this article have no conflicts of interest.

Received for publication Oct 1, 2021; revisions received Oct 1, 2021; accepted for publication Oct 8, 2021; available ahead of print Oct 13, 2021.

Address for reprints: James Tatoulis, AM, MBBS, MS, MD, FRACS, FCSANZ, Department of Cardiothoracic Surgery, Medical Centre, Royal Melbourne Hospital, Suite 28, 300 Grattan St, Parkville, Australia 3050 (E-mail: james.tatoulis@ mh.org.au).

JTCVS Techniques 2021;10:112-3

2666-2507

Copyright (C 2021 The Author(s). Published by Elsevier Inc. on behalf of The American Association for Thoracic Surgery. This is an open access article under the CC BY-NC-ND license (http://creativecommons.org/licenses/by-nc-nd/4.0/). https://doi.org/10.1016/j.xjtc.2021.10.010
}

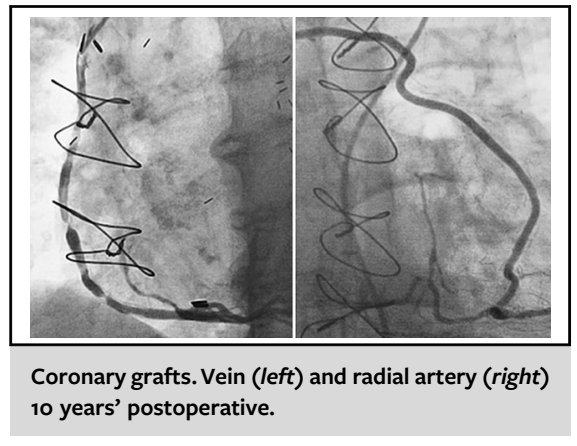

CENTRAL MESSAGE

As vein grafts are widely used, measures to enhance their patency are paramount, and some hold promise. Multiarterial grafting including the use of the radial artery is a readily available solution.

unacceptably high rates of leg wound infections, probably even worse in patients with diabetes and obesity. Endoscopic SVG harvest with low infection rates is now standard, and it is unlikely that this will change.

The excellent results for LITA-SVG Y grafts also emanate from only one center. Many would be uncomfortable anastomosing a 4 to $5 \mathrm{~mm}$ diameter SVG to a 2 to $3 \mathrm{~mm}$ LITA, with concerns over distortion and vascular steal. Most would consider this only as a bail-out strategy.

External support of the SVG to reduce intimal hyperplasia and to enhance patency is elegant and attractive via its simplicity and has potential if the current large study results are favorable and it is not costly. Endoscopic SVG harvesting has been repeatedly associated with high SVG failure rates. ${ }^{5}$ The authors have not suggested improvements nor potential advances - dedicated harvesters? Improved endoscopic technology? Storage solutions to preserve endothelial integrity have not provided convincing results. The "DuraGraft" studies may contribute, but answers will be some years away.

Pharmacotherapy advances have the greatest potential to improve SVG patency. Newer antiplatelet drugs or combinations thereof, have had marginal benefit-more so in off-pump CABG. They appear to predominantly influence perioperative SVG patency but are worth further 
exploration. Incidentally, there is little information re their efficacy on arterial grafts.

Statins and antilipid immunoglobulins ${ }^{6}$ hold the most promise, especially in combating long-term atherothrombotic changes in SVG, and they are simple to administer. One would predict substantial activity in this domain. Potential problems include multi-medication fatigue, nonadherence (hopefully countered by regular patient review), and cost. It is extremely important that this modality is vigorously pursued.

The "elephant in the room" remains the (non)use of multiple arterial grafts. Reasons for MAG hesitancy are not clear. MAG is supported in revascularization guidelines, ${ }^{2}$ including the radial artery, which is readily available, and can be harvested and used identically to SVG, but with greater impact-better patencies and long-term outcomes. $^{1,7}$

Although every endeavor to improve SVG patency is important and to be encouraged, the solution "is on our doorstep," ie, greater use of MAG. It is essential to focus on ways to enhance graft patency and prognosis in CABG by encouraging both the use of MAG while simultaneously implementing means to enhance SVG patency, succinctly presented in this important contribution.

\section{References}

1. Gaudino M, Benedetto U, Fremes S, Ballman K, Biondi-Zoccai G, Sedrakyan A, et al. Association of radial artery graft vs saphenous vein graft with long-term cardiovascular outcomes among patients undergoing coronary artery bypass grafting: a systematic review and meta-analysis. JAMA. 2020; 324:179-87.

2. Aldea GS, Bakaeen FG, Pal J, Fremes S, Head SJ, Sabik J, et al. The Society of Thoracic Surgeons clinical practice guidelines on arterial conduits for coronary artery bypass grafting. Ann Thorac Surg. 2016;101:801-9.

3. Sabik JF III. Understanding saphenous vein graft patency. Circulation. 2011;124: 273-5.

4. Vervoort D, Malik A, Fremes SE. The evolving evidence base for coronary artery bypass grafting and arterial grafting in 2021: how to improve vein graft patency. $J$ Thorac Cardiovasc Surg Tech. 2021;10:102-9.

5. Lopes RD, Hafley GE, Allen KB, Ferguson TB, Peterson ED, Harrington RA, et al Endoscopic versus open vein-graft harvesting in coronary-artery bypass surgery. $N$ Engl J Med. 2009;361:235-44.

6. Gao J, Wang H-B, Xiao J-Y, Ren M, Reilly KH, Li Y-M, et al. Association between proprotein convertase subtilisin/kexin type 9 and late saphenous vein graft disease after coronary artery bypass grafting: a cross-sectional study. BMJ Open. 2018;8: e021951.

7. Tatoulis J. The radial artery: an important component of multi-arterial coronary surgery. considerations for its optimal harvest. J Thorac Cardiovasc Surg Tech. 2021;5:46-55. 